\title{
Factorial Design based Medium Optimization for the Improved Production of Biosurfactant by Mucor polymorphosphorus
}

\author{
Patrícia Mendes Souza ${ }^{1,4}$, Marta Freitas-Silva ${ }^{1,4}$, Thayse Alves de Lima e Silva ${ }^{1,4}$, \\ Grayce K.B. Silva ${ }^{1,4}$, Marcos A.B. Lima ${ }^{2,4}$, Aline Elesbão Nascimento ${ }^{4}$, Nathália Marques ${ }^{3,4}$, \\ Vanessa Pimentel Santos ${ }^{3,4}$, Laura Truan Oliveira ${ }^{3,4}$ and Galba M.Campos-Takaki ${ }^{4} *$ \\ ${ }^{1}$ National Program of Post-Doctorate (PNPD) -CAPES, Catholic University of Pernambuco, \\ 50050-590, Recife, Pernambuco, Brazil; \\ ${ }^{2}$ Department of Biology, Federal Rural University of Pernambuco, 52.171-900 \\ Recife, Pernambuco, Brazil; \\ ${ }^{3}$ Master in Development of Environmental Processes, Catholic University of Pernambuco, \\ 50.050-900 Recife, Pernambuco, Brazil. \\ ${ }^{4}$ Nucleus of Research in Environmental Sciences and Biotechnology, Catholic University of \\ Pernambuco, 50050-590, Recife, Pernambuco, Brazil \\ *Corresponding author
}

\section{Keywords}

Optimization;

Factorial Desing;

Mucor

polymorphosphorus;

Tensio-active agents;

Agro-industrial

residues;

Biosurfactant.

\section{Article Info}

Accepted:

20 October 2016

Available Online:

10 November 2016

\section{A B S T R A C T}

The biosurfactants are compounds of microbial origin that exhibit surfactant property, low toxicity and high biodegradability. In this study was to evaluate the production of surfactant by Mucor polymorphosphorus, isolated from Caatinga soil from Brazil, using agro-industrial residues. The experiments were monitored by Central Composite Rotational Design (CCRD) using as variable response the reduction of the surface tension. The factors selected for study were soybean waste oil and corn steep liquor as substrates. The spore suspension containing $10^{7}$ sporangiospores $/ \mathrm{mL}$ were inoculated in Erlenmeyer flasks containing the alternative medium according factorial design; The flasks were grown during 96 hours, at $28^{\circ} \mathrm{C}$ and $150 \mathrm{rpm}$. All factors studied were important within the ranges investigated. The empirical forecast model developed regarding effective nutritional factors was adequate for explain $84.79 \%$ of the variation observed on biosurfactant production. Maximal reduction in surface tension of $33.2 \mathrm{mN} . \mathrm{m}^{-1}$ with final $\mathrm{pH} 6.5$ was obtained under the optimal conditions of corn steep liquor $4.61 \%$ and soybean oil after frying $7.5 \%$. These results demonstrated that the factorial design is adequate for identifying the optimal conditions for biosurfactant production by fungi.

\section{Introduction}

Surfactants are amphipathic molecules, which reduce the interfacial tensions between liquids, solids and gases and confer excellent detergency, emulsifying, foaming and other versatile chemical process. Biosurfactants constitute one of the main 
classes of natural surfactants produced by the microorganisms, being classified in accordance with their chemical composition or microbial origin. These polymers have attracted, in the last few years, considerable interest due to biodegradable nature, low toxicity and diversity of applications (AlSulaimani et al., 2011; Rodrigues et al., 2015).

The high cost in the production of biosurfactants, mainly determined by the high cost raw material and low product concentration, inhibited their competition with chemical surfactants. A positive strategy to reduce biosurfactant production costs is the use of inexpensive substrates or high-efficiency strain to increase its productivity. The used frying oils in large quantities are hence considered as a problematic waste product contributing to the pollution of the environment. Overall, the waste frying oil disposal is a growing problem needing effective solution. Biotransformation of frying oils by microorganisms into biosurfactants may be the effective way to solve the problem above (Luo and Zhi et al., 2013; Coronel-León et al., 2016).

Reducing the overall costs of biosurfactant production usually depends on improving the strain, the use of low cost raw materials such as agricultural and industrial wastes as substrates, the use of process scale-up and the use of advanced computer-based techniques for process control and optimization (Shekhar et al., 2015).

Optimizing the composition of the medium is an important issue in developing economically feasible biosurfactant production processes. Microbial produced surfactants or biosurfactants have attracted attention because of their low toxicity, biodegradability, and ecological acceptability. However, they must compete with surfactants of petrochemical origin in three respects-cost, functionality, and production capacity to meet the needs of the intended application (Ahmad et al., 2016; Rossi et al., 2016).

The aim of the present study was to optimize the production of biosurfactants by Mucor polymorphosphorus using low cost substrates, on a flask scale.

\section{Experimental Section}

\section{Microorganism}

Mucor polymorphosphorus (URM 1044) was kindly supplied from the Culture Collection Mycology Department UFPE, and maintained in the Culture Collection UCP (Universidade Católica de Pernambuco) and registered in the World Federation for Culture Collection - WFCC, at $5^{\circ} \mathrm{C}$ on Sabouraud dextrose agar medium (SAB). The culture was transferred each four months to fresh agar slants SAB medium to maintain viability.

\section{Biosurfactant Production}

All optimization experiments were carried out in $250 \mathrm{~mL}$ Erlenmeyer flasks containing $100 \mathrm{~mL}$ of basal medium. The basal medium consisted of corn steep liquor and soybean oil after frying dissolved in distilled water, in various concentrations, according to the experimental designs. The media were sterilized by autoclaving at $121^{\circ} \mathrm{C}$ for 20 min. The $\mathrm{pH}$ of the media was adjusted to 5.5. The experiments were monitored by Central Composite Rotational Design (CCRD) $2^{2}$, (Table 1), using as variable response the reduction of the surface tension. Aliquots $(1 \mathrm{~mL})$ of the spore suspension containing $10^{7}$ spores $/ \mathrm{mL}$ were inoculated in Erlenmeyer flasks. The 
cultures were grown during 96 hours at $28^{\circ} \mathrm{C}$, and kept under agitation $(150 \mathrm{rpm})$.

\section{Surface Activity Assay}

Surface tension was determined on cell-free broth obtained by centrifuging the cultures at $10,000 \times \mathrm{g}$ for $15 \mathrm{~min}$ with a Tensiometer model Sigma 70 (KSV Instruments Ltd., Finland) using the Du Nouy ring method at room temperature $\left( \pm 28^{\circ} \mathrm{C}\right)$. Measurements of surface tension from distilled water were used as controls (Kuyukina et al., 2005).

\section{Results and Discussion}

This work describes the use of post-frying soybean oil and corn steep liquor as low cost medium components for biosurfactant production by the filamentous fungus Mucor polymorphosphorus (URM 1044). This production was detected by surface tension becoming lower when the microorganism was cultivated on water to which of postfrying soybean oil and corn steep liquor were added, in various concentrations. The optimization process was conducted for Factorial Design DCCR $2^{2}$. Decesaro et al (2013), considered as good producer of biosurfactant those microorganisms which reduce the surface tension of water of 72 $\mathrm{mN} / \mathrm{m}$ to $40 \mathrm{mN} / \mathrm{m}$. Table 2 presents the surface tension of metabolic liquid, free of cells, produced by $M$. polymorphosphorus. The results showed activities surfactants in assay 5 (4.61\% of corn steep liquor and $7.5 \%$ after frying oil) $33.2 \mathrm{mN} \mathrm{m}$ final $\mathrm{pH}$ of 6.5. Qazi et al (2014) using sucrose and yeast extract, as carbon and nitrogen sources, respectively for the production of biotensoactives with Fusarium sp. BS-8 obtained a reduction of the surface tension (air / water interface) of $72 \mathrm{mN} / \mathrm{m}$ to 32 $\mathrm{mN} / \mathrm{m}$. In another study, the biosurfactant from Candida bombicola URM 3718 cultivated in a low cost medium formulated with 5\% corn steep liquor, 5\% molasses and $5 \%$ soybean waste frying oil as substrates reduced the surface tension to values around $30 \mathrm{mN} / \mathrm{m}$ after $144 \mathrm{~h}$ (Luna et al., 2016), while the biosurfactant from Candida guilliermondii UCP0992 cultivated in $2.5 \%$ waste frying oil, $2.5 \%$ corn steep liquor and $4.0 \%$ molasses a reduced the surface tension to $28 \mathrm{mN} / \mathrm{m}$ (Sarubbo et al., 2016).

The analysis of the surface tension values is listed in Table 2. The effects of corn steep liquor and post-frying oil on surface tension, as well as the interaction between them, in the Central Composite Rotational Design (CCRD) $2^{2}$ are shown in Figure 1. The Pareto chart clearly shows that corn steep liquor concentration is by far the most important factor affecting the reduction of surface tension of cell-free culture broth, followed by post-frying oil concentration and corn steep liquor - post-frying oil interaction. As can be seen in the Pareto chart, the increase in post-frying oil concentration influenced negatively, in a statistically significant way, the increase in surface tension, leading to lower surface tension. The increase in corn steep liquor concentration also influenced negatively, in a statistically significant way, the increase in surface tension, leading to lower surface tension. On the other hand, the corn steep liquor - post-frying oil interaction contributes in a statistically significant way to the increase of surface tension in the culture medium. Figure 1 also shows that curvature effect crosses the $95 \%$ confidence level, indicating the proximity of the optimum point.

Table 3 displays a summary of ANOVA representing the results of the fit of linear response model. According to Box (1973), Fisher's variance ratio must be large enough to justify a very high degree of adequacy of the model and indicate that the treatment 
combinations are highly significant. In this table, the value of the explained variance $\left(R^{2}=84.79\right)$ ensures adequate fit $(R=0.92)$; thereby validating the model.

According to Nathans et al., (2012), a model is more than another template set, their values when the correlation coefficient approaches 1.0 , the value of the variance approaches $100 \%$. These authors state that the larger the calculated value of the test F1 is more significant tabulated model and the smaller the calculated F2 test than the more predictive F2 test is tabulated model. Thus, it can be stated that the model represented by Equation 1 is statistically significant, is fitted to the experimental data and thus can predict the experimental results with better accuracy than other models.

Table.1 Factorial design - Delineation central composite rotational DCCR 22 for Mucor polymorphosphorus

\begin{tabular}{clllll}
\hline \multirow{2}{*}{ Factor } & \multicolumn{5}{c}{ Level } \\
\cline { 2 - 6 } & $\mathbf{- 1 . 4 1}$ & $\mathbf{- 1}$ & $\mathbf{0}$ & $\mathbf{+ 1}$ & $\mathbf{+ 1 , 4 1}$ \\
\hline Corn Steep Liquor (\%)/v) & 0.38 & 1 & 2.5 & 4 & 4.61 \\
\hline $\begin{array}{c}\text { Soybean Oil After Frying } \\
(\% \mathbf{\%} / \mathbf{v})\end{array}$ & 3.98 & 5 & 7.5 & 10 & 11.02 \\
\hline
\end{tabular}

Table.2 Surface Tension according to first full factorial design - DCCR 22 using Mucor polymorphosphorus after $96 \mathrm{~h}$ incubation with shaking

\begin{tabular}{ccccc}
\hline & \multicolumn{2}{c}{ Components } & & \\
\cline { 2 - 3 } Assay & $\begin{array}{c}\text { Culture medium } \\
\text { Corn steep } \\
\text { liquor } \\
(\mathbf{\%})\end{array}$ & $\begin{array}{c}\text { Soybean oil } \\
\text { After frying } \\
(\mathbf{\%})\end{array}$ & $\begin{array}{c}\text { Surface tension } \\
(\mathrm{mN} / \mathrm{m})\end{array}$ & $\mathrm{pH}$ \\
$\mathbf{1}$ & +1 & +1 & 34.3 & \\
\hline $\mathbf{2}$ & -1 & +1 & 35.7 & 6.45 \\
\hline $\mathbf{3}$ & +1 & -1 & 34.4 & 5.71 \\
\hline $\mathbf{4}$ & -1 & -1 & 35.8 & 5.93 \\
\hline $\mathbf{5}$ & $\mathbf{1 . 4 1}$ & $\mathbf{0}$ & $\mathbf{3 3 . 2}$ & 5.54 \\
\hline $\mathbf{6}$ & 0 & -1.41 & 35.0 & $\mathbf{6 . 5 0}$ \\
\hline $\mathbf{7}$ & -1.41 & 0 & 37.0 & 6.00 \\
\hline $\mathbf{8}$ & 0 & +1.41 & 34.7 & 5.66 \\
\hline $\mathbf{9}$ & 0 & 0 & 35.6 & 6.35 \\
\hline $\mathbf{1 0}$ & 0 & 0 & 34.9 & 5.48 \\
\hline $\mathbf{1 1}$ & 0 & 0 & 35.3 & 6.32 \\
\hline $\mathbf{1 2}$ & 0 & 0 & 34.5 & 6.46 \\
\hline & & & & 6.30 \\
\hline
\end{tabular}


Table.3 The analysis of variance (ANOVA) model that best fit the experimental data at $95 \%$ confidence level

\begin{tabular}{l|l|l|l|l}
\hline Source of variation & Sum of squares & Degrees of freedom & Mean square & $\mathrm{F}_{\text {calc }}$ \\
\hline Regression & 8.485 & 4 & 2.121 & \\
\hline Residual & 1.542 & 7 & 0.220 & 9.631 \\
\hline Lack of fit & 0.854 & 4 & 0.214 & \\
\hline Pure error & 0.687 & 3 & 0.229 & 0.932 \\
\hline Total & 10.007 & 11 & & \\
\hline$\%$ explained variance & \multicolumn{3}{l}{} & 84.79 \\
\hline \% maximum explainable variance & 0.9208 \\
\hline
\end{tabular}

$\mathrm{F}_{\text {tab } 1(4,7)}=4.12 ; \mathrm{F}_{\text {tab 2 (4,3) }}=9.117$

Fig.1 Pareto's Chart of standardized effects for (1) corn steep liquor and (2) soybean oil postfrying using surface tension as response variable. The point at which the effect estimates were statistically significant $(\mathrm{p}=0.050)$ is indicated by dashed line

Pareto Chart of Standardized Effects; Variable: SURFACE TENSION

DV: SURFACE TENSION

(1)CORN STEEP LIQUOR(L)

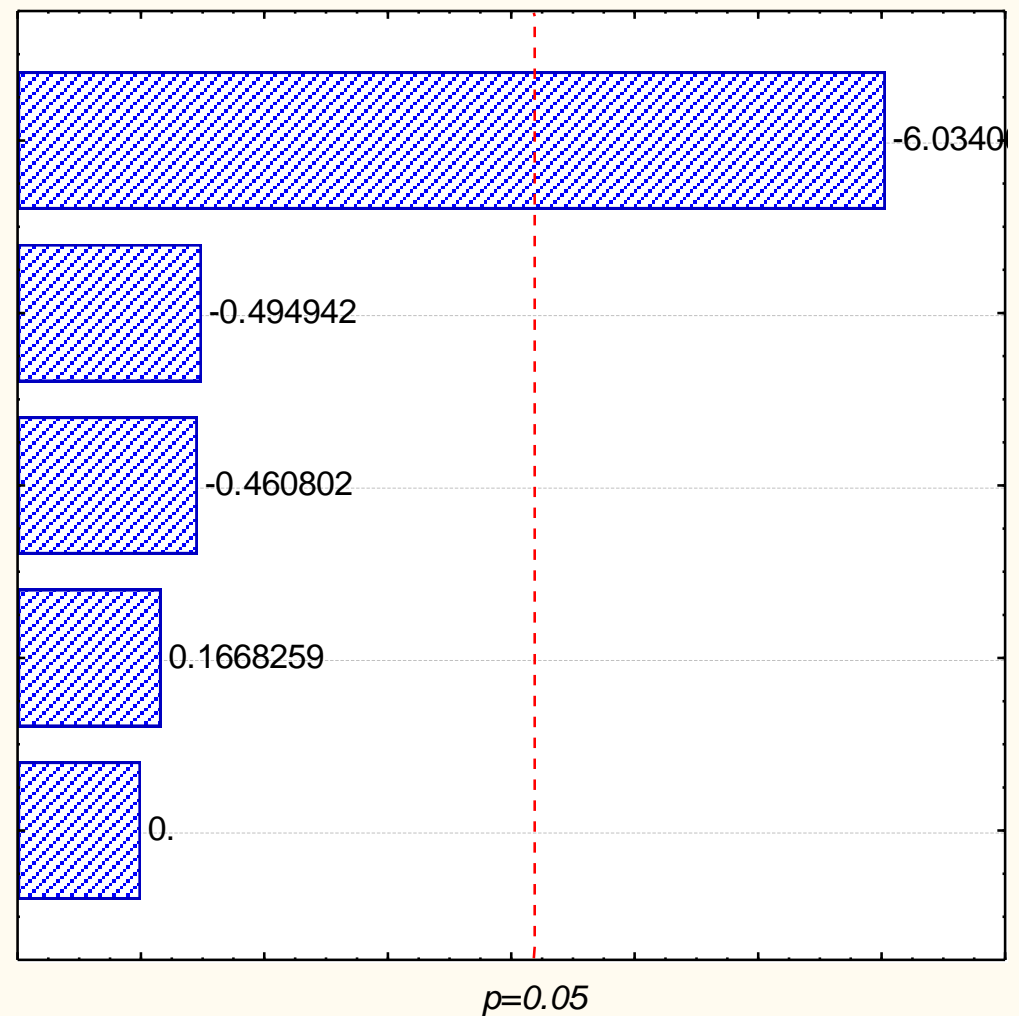

Standardized Effect Estimate (Absolute Value) 
Fig.2 Surface tension response surface showing interaction between soybean post-frying oil and corn steep liquor concentrations

Fitted Surface; Variable: Surface tension $(\mathrm{mN} / \mathrm{m})$

2 factors, 1 Blocks, 12 Runs; MS Pure Error=0.2291667

DV: Surface tension $(\mathrm{mN} / \mathrm{m})$

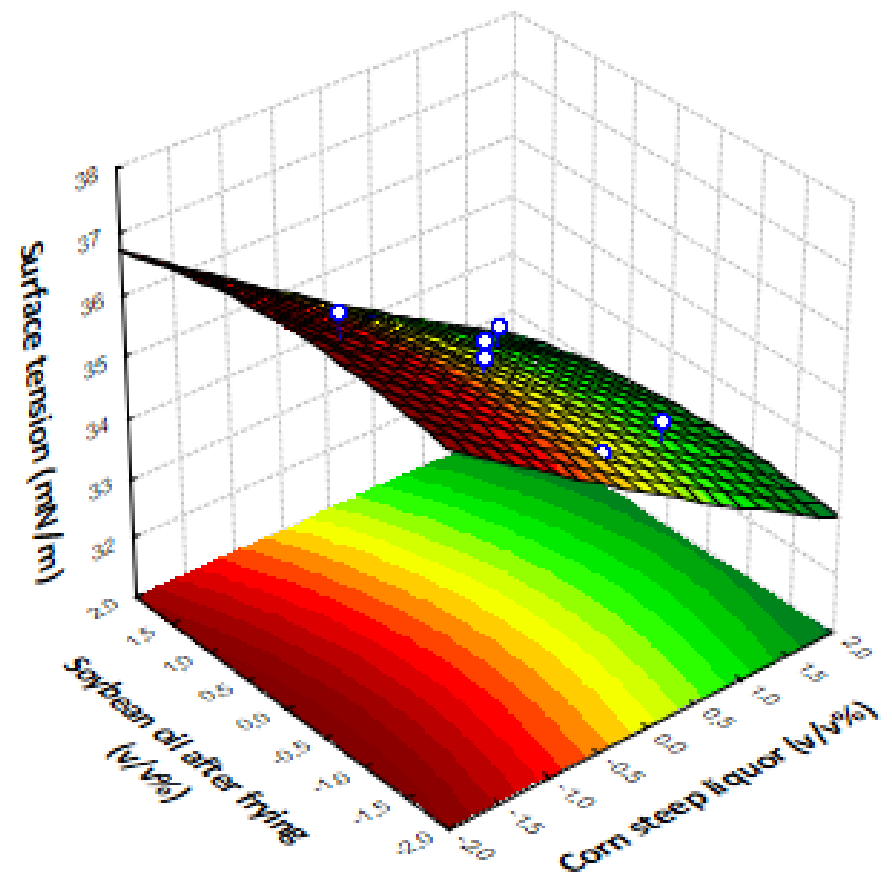

Equation 1 represents the model that best fit the experimental data and experimental. This model has a greater influence on surface tension corn steep liquor than soybean oil. However, one can not overlook the influence of soybean oil, because in a second it can influence response (Figure 2).

$\left[>\mathrm{Y}=36,2592-0,7531 * \mathrm{x} 1+0,1935^{*} \mathrm{x} 2\right.$ $\left.+0,0143 * \mathrm{x} 1 .{ }^{\wedge} 2-0,0150 * \mathrm{x} 2 .^{\wedge} 2\right]$

(Eq.1)

Observing the analysis according to Nathans et al., (2012), quoted above, we note that the model, although it was the best that stood out among the rest, although it can be considered highly predictive (F2calc $<<$ F2tab). This way, you can use it in process optimization study therefore within the range of the study; it can predict the experimental results with better accuracy than other models.

Equation 2 represents the model used to optimize the process under study. This model has a greater influence on the $\mathrm{pH}$ of corn steep liquor, but the influence of soybean oil was not negligible as in the first. 
[〉> Y2 $=5,0646+0,2083 * \mathrm{x} 1+0,0938 * \mathrm{x} 2-$ $0.0380 * \mathrm{x} 1 \wedge 2-0,0062 * \mathrm{x} 2 \wedge 2+0,0233 * \mathrm{x} 1 * \mathrm{x} 2]$ Eq.2)

In conclusion, the Mucor polymorphosphorus was able to produce a surfactant using as culture medium, corn steep liquor (4.61\%) and post-frying soybean oil $(7.5 \%)$, thereby reducing the surface tension of water from $72 \mathrm{mN}$ m to $33.2 \mathrm{mN} / \mathrm{m}$. The results suggest the effectiveness and feasibility of using Central Composite Rotational Design (CCRD) to identify the best medium composition for the enhanced production of biosurfactant. formulation of an alternative and inexpensive medium, based on the corn steep liquor, as well as reuse of soybean oil post-frying to produce biosurfactants could be reduce the production cost, enhancing the feasibility of the commercial application of this promising biomolecule.

\section{Acknowledgments}

The authors are grateful to Foundation for the Support of Science and Technology of the State of Pernambuco (FACEPE) for granting post-doctoral scholarships, to Coordination for the improvement of Higher Level Education Personnel (CAPES), the National Council for Scientific and Technological Development (CNPq) and the Nucleus of Research in Environmental Sciences and Biotechnology (NPCIAMB) of Catholic University of Pernambuco, Brazil.

\section{Conflicts of Interest}

The authors declare no conflict of interest.

\section{References}

Ahmad, Z., Arshad, M., Asghar, H.N., Sheikh, M.A., and Crowley, D.E. 2016. Isolation, Screening and
Functional Characterization of Biosurfactant Producing Bacteria Isolated from Crude Oil Contaminated Site. Int. J. Agri. Biol., 18(3): 542-548. Al-Sulaimani, H., Joshi, S., Al-Wahaibi, Y., Al-Bahry, S., Elshafie, A., and AlBemani, A. 2011. Microbial biotechnology for enhancing oil recovery: current developments and future prospects. Biotechnol. Bioinf. Bioeng., 1(2): 147-158.

Coronel-León, J., Marqués, A. M., Bastida, J., and Manresa, A. 2016. Optimizing the production of the biosurfactant lichenysin and its application in biofilm control. J. Appl. Microbiol., 120(1): 99-111.

Decesaro, A., Rigon, M.R., Thomé, A., and Colla, L.M. 2013. Production of biosurfactants by microrganisms isolated from soil contaminated with diesel oil. Química Nova, 36(7): 947954.

Kuyukina, M.S., Ivshina, I.B., Makarov, S.O., Litvinenko, L.V., Cunningham, C.J., and Philp, J.C. 2005. Effect of biosurfactants on crude oil desorption and mobilization in a soil system. Environ. Int., 31(2): 155-161.

Luna, J.M., Santos Filho, A.S., Rufino, R.D., and Sarubbo, L.A. 2016. Production of Biosurfactant from Candida bombicola URM 3718 for Environmental Applications. Chem. Engi., 49: 583-588.

Luo, Z., Yuan, X. Z., Zhong, H., Zeng, G. M., Liu, Z. F., Ma, X. L., and Zhu, Y. Y. 2013. Optimizing rhamnolipid production by Pseudomonas aeruginosa ATCC 9027 grown on waste frying oil using response surface method and batch-fed fermentation. $J$. Central South University, 20: 10151021.

Nathans, Laura, L., Oswald, Frederick, L., \& Nimon, Kim. 2012. Interpreting 
Multiple Linear Regression: A Guidebook of Variable Importance. Practical Assessment, Res. Evaluation, 17(9).

Neto, B.B., Scarminio, I.S., and Bruns, R.E. 2001. Como fazer experimentos. Unicamp, Campinas.

Qazi, M.A., Kanwal, T., Jadoon, M., Ahmed, S., and Fatima, N. 2014. Isolation and characterization of a biosurfactant-producing Fusarium sp. BS-8 from oil contaminated soil. Biotechnol. progress, $30(5)$ : 1065-1075.

Rodrigues, C., Cassini, S.T.A., Antunes, P. W.P., Pinotti, L.M., de Pinho Keller, R., and Gonçalves, R.F. 2015. Lipase and Surfactant Production by Fungi Isolated of Oily Residues of Environmental Sanitation in Liquid and Solid Phase Reactors. Int. J. Appl., 5(3): 46-54.

Rossi, E.M., Beilke, L., Kochhann, M., Sarzi, D.H., and Tondo, E.C. 2016.
Biosurfactant Produced by Salmonella enteritidis SE86 Can Increase Adherence and Resistance to Sanitizers on Lettuce Leaves (Lactuca sativa L., cichoraceae). Frontiers in Microbiol., 7: 1-9.

Rufino, Raquel, D. et al. Experimental design for the production of tensioactive agent by Candida lipolytica. $J$. Industrial

Microbiol.

Biotechnol., 35(8): 907-914.

Sarubbo, L.A., de Luna, J.M., Rufino, R.D., and Brasileiro, P.P. 2016. Production of a Low-cost Biosurfactant for Application in the Remediation of Sea water Contaminated with Petroleum Derivates. Chem. Engi., 49: 523-528.

Shekhar, S., Sundaramanickam, A., and Balasubramanian, T. 2015 Biosurfactant producing microbes and their potential applications: A review. Critical Reviews in Environ. Sci. Technol., 45(14): 1522-1554.

\section{How to cite this article:}

Patrícia Mendes Souza, Marta Freitas-Silva, Thayse Alves de Lima e Silva, Grayce K.B. Silva, Marcos A.B. Lima, Aline Elesbão Nascimento, Nathália Marques, Vanessa Pimentel Santos, Laura Truan Oliveira and Galba M.Campos-Takaki. 2016. Factorial Design based Medium Optimization for the Improved Production of Biosurfactant by Mucor polymorphosphorus. Int.J.Curr.Microbiol.App.Sci. 5(11): 898-905. doi: http://dx.doi.org/10.20546/ijcmas.2016.511.103 